accept responsibility for reassessment of patients found to be unsuitable for care in the home within an agreed period of placement, generally six months.

\section{Concluding remarks}

This document has been produced against the background of a rapidly changing situation. It is offered because the private sector increasingly provides care for arguably the most vulnerable section of the population, the elderly mentally ill. It is hoped that discussions will arise from this document which will further clarify the issues we have raised-for proper assessment before placement; for treatment and rehabilitation as well as care; for care in environments which meet the needs and wishes of elderly people, where they might find a secure haven, free from the risk of exploitation. We also hope to see a real dialogue developing between the private and public service care provides on issues such as the planning and operation of care services for the elderly with mental disorder.

Approved by Council March 1987
REFERENCES

'Chancellor's Statement: Social Security (1984) Press Release, Department of Health and Social Security, 12 November 1984.

${ }^{2}$ Registered Homes Act (1984) Chapter 23, including statutory Instruments No 1346 and No 1348(C29).

${ }^{3}$ Capewell, A. E., Primrose, W. R. \& Macintyre, C. (1986) Nursing dependency in registered nursing homes and long-term geriatric wards in Edinburgh. British Medical Journal, 292, 1719-1721.

4Supplementary Benefit and Residential Care (1985) Report of a Joint Central and Local Government Working Party.

${ }^{5}$ Home Life: A Code of Practice for Residential Care (1984) Report of a Working Party sponsored by the DHSS and convened by the CPA; published by the Centre for Policy on Ageing.

'National association of Health Authormties (1985) Registration and Inspection of Nursing Homes: A Handbook for Health Authorities.

\title{
Psychiatrists and General Management
}

\author{
David TAIT, Consultant Psychiatrist, Murray Royal Hospital, Perth PH2 7BH; Chairman, Management Group, \\ Scottish Division
}

Those who distrust the 'straw poll' at the party conference or outside the polling station should not read on, those who feel that such exercises can be illuminating may be interested in the following impression of Scottish psychiatrists' views on general management.

The Study

At the Quarterly Meeting of the Scottish Division of the Royal College of Psychiatrists on 5 December, 1986 the author gave out a questionnaire on behalf of the newlyformed Management Group. Thirty-seven questionnaires were returned, completed to various degrees; the respondents included 25 Consultants, one Medical Commissioner from the Mental Welfare Commission, three Senior Registrars and six Registrars. Although less than $10 \%$ of Scottish psychiatrists' views are presented, they came from 20 different services, about half the total in the country. The questionnaire was discussed and completed during one part of the meeting. Many respondents replied only in part, and most questions permitted more than one response to the 'stem', so it is the proportion of yes to no answers which is of most interest.
1. The Griffiths ideology

Do you think the Griffiths proposals are:

a) Irrelevant to the NHS?

(b) May enhance patient care through better management?

(c) May damage patient care through inappropriate management?
YES NO

32

$31 \quad 2$

27
These results seem clear cut-only two respondents thinking Griffiths' ideas are irrelevant, only two thinking they are powerless to improve patient care, only six believing they can do no harm. The commonest pattern of replies to the question (from 22 of 37 respondents) was no-yes-yes; Scottish psychiatrists clearly see Griffiths as relevant, and powerful for good or evil. This most recent reorganisation is certainly not viewed as merely cosmetic. 


\section{Board General Managers \\ Since the appointment of the BGM in your Health Board:}

(a) Has there been any perceptible change?

(b) Has your access to management improved?

(c) Has this improved care for your patients?

I interpret this to mean that Board General Managers may be developing a high public or political profile, but that has yet to filter down to clinicians. Perhaps it is unreasonable to expect patient care to have been affected at so early a date after the appointment of Board General Managers (three respondents), but Board General Managers might be disappointed that only three clinicians perceive that their access to management has improved.

3. Unit Structure YES NO

(a) Were you consulted adequately on Unit Structure vis à vis your own Service?

(b) Do you think your new Unit Structure is the best alternative for your service?

16

$16 \quad 14$

$19 \quad 9$

There might be similar disappointment in that nearly half of the respondents felt themselves to be inadequately consulted on Unit Structure (and such replies were not restricted to those from particular Health Boards). Nor should there be complacency about the majority who are happy with their Unit Structures-there is perhaps some inevitability about specialty units in cities and geographical units in the country. It is noteworthy that six of the nine dissatisfied psychiatrists referred to their own mixed units, which may be the most difficult to manage.

4. Unit Management Teams

Should clinical input to a UMT be:

(a) Managerial (Physician Superintendent or equivalent)?

(b) Representative (Chairman of Division or equivalent)?

Clinicians seem to be grasping the managerial nettle, albeit with gardening gloves on-the 26 psychiatrists pro- posing managerial input include nine who also want representative influence (to control our colleagues who declare themselves as managers perhaps?). Only five respondents proposed clinical input without managerial responsibilities.

\section{Hospital/Service Management}

YES NO Which of the following do you think are relevant:

(a) Tripartite management (psychiatrist, nurse and administrator)?

(b) Tripartite management with psychiatrist as primus inter pares?

196

c) Management by clinical objectives?

(d) The therapeutic community?

(e) Clinical budgeting?

$16 \quad 12$

332

$7 \quad 15$

$17 \quad 9$

The final section comprised testing audience reaction to several quite different ideas about management at hospital or service level. Most seemed happy with traditional tripartite management but only a slim majority felt that the psychiatrist was the natural leader. Dr Jim Affleck's phrase "management by clinical objectives", by which it is implied that patient needs must be the determinants of management structures, found overwhelming support. By contrast the ideal of the therapeutic community may be difficult to transpose from an institutional to an extramural setting. Opinion was divided with respect to clinical budgeting, irrelevance rather than fear of the unknown may be the main deterrent to clinicians.

\section{Comment}

If we can extrapolate from this study a guess as to the feelings of all Scottish psychiatrists, it seems that aspiring Clinical Managers do have a mandate from their colleagues in terms of their recognising the significance of Griffiths, although this is tempered by their not having experienced tangible benefits from the introduction of the General Management Function as yet. By and large Clinical Managers will have the support of their fellows if they become involved with Unit Management Teams as Managers of Services, rather than as representatives of their colleagues, but the clearest message about management at 'shop floor level' is that the patient must always come first.

\section{'The AIDS Letter'}

This new bi-monthly subscription newsletter covers all aspects of AIDS and HIV and is based on information collected from research and treatment centres around the world. Professor Michael Adler, one of Britain's leading experts on AIDS, and his colleagues at the Middlesex Hospital, London, check the copy for each issue to ensure the reliability of its information. Further information: Publications Department, Royal Society of Medicine, 1 Wimpole Street, London W1M 8AE.

\section{Child Sexual Abuse: Training-the way forward}

The National Children's Bureau and the Training and Advisory Group on the Sexual Abuse of Children (TAGOSAC) are organising a conference on the above topic on 7 September 1987 at the Institute of Education, Bedford Way, London WCl. Further information: Helen Armstrong, Development Officer, National Children's Bureau, 8 Wakley Street, London ECIV 7QE (telephone 01278 9441). 